\title{
Feasibility analysis of clean energy power generation and heating project under $\mathrm{BOO}$ mode
}

\author{
Zengqiang Zhang ${ }^{1,}{ }^{*}$, Ming Gao ${ }^{1}$, Gaoshan $\mathrm{Fu}^{2}$, Yelin $\mathrm{Xu}^{1}$, and Chaoshan $\mathrm{Xin}^{1}$ \\ ${ }^{1}$ Economic and Technological Research Institute of State Grid X injiang Electric Power Co.Ltd, Xinjiang, China \\ ${ }^{2}$ State Grid X injiang Electric Power Co.Ltd, X injiang, China
}

\begin{abstract}
Clean energy for power generation and heating is an important route for clean energy consumption in the northern regions with abundant wind and solar resources. However, in the promotion of clean heating projects, there are problems such as high investment costs and high pressure from government financial subsidies. Therefore, it is urgent to explore new economically feasible business models suitable for clean energy power generation and heating. This paper first proposes a new business model of clean energy power generation and heating under the BOO operation mode of the PPP business model. Secondly, from the perspective of investment value, the net present value method is used to analyze the economic benefits of the project, and the cash flow of the clean energy power generation and heating project is analyzed. Finally, combined with actual cases in a certain area in X injiang, the net present value method is used to analyze the calculation examples, verify the economic feasibility of the proposed business model, and provide guidance for the further promotion of clean energy power generation and heating projects.
\end{abstract}

\section{Introduction}

The traditional winter coal-fired heating method in the north has brought lots of pressure on the environment and development. Heating in a low-carbon and clean way is a need for environmental protection. At present, the implementation of clean heating pilot projects mostly relies on national and local government policy support to ensure project income. However, with the change of national policies, some subsidy costs have been cancelled, which puts huge financial pressure on the development of power grid companies and faces difficulties in promoting clean heating. Therefore, it is necessary to explore and analyze the business model suitable for clean energy power generation and heating and its economic benefits.

In terms of the business model of public utilities, Literature [1] explores the public parking lot project from the perspective of the whole life, and establishes the costbenefit analysis model of the parking lot of different building forms under different PPP models. Literature [2] introduces the $\mathrm{BOO}$ model in the waste treatment project, and uses the "04 scoring method" in value engineering to score the responsible entities of the risks and their corresponding share of responsibilities to share the risks reasonably. Literature [3] uses the BOO model to build a small-scale water quality automatic monitoring system on the shore, and compares the actual implementation of the project with the traditional way to build a small-scale water quality automatic monitoring system on the shore to compare the advantages and disadvantages. The advantages of the monitoring system outweigh the disadvantages. However, there is currently little exploration of the business model of power engineering projects, and further research is needed on the application of business models that have been applied in public utilities to clean energy power generation and heating projects.

In terms of cost-benefit analysis, the economic evaluation of power engineering projects can provide an important basis for power investment decision-making[46]. To evaluate the economic benefits of power engineering projects, it is necessary to analyze the economic benefits of the investment subject, compare the useful results of power technology progress with labor costs, measure the economic rationality between its input and output, and scientifically calculate, analyze and demonstrate economic indicators[7]. Existing research methods for the economic analysis of power grid engineering projects include comparing the economic benefits of different planning schemes, or analyzing the investment cost of the project and analyzing the economics of this investment during the entire life cycle of the asset.

Starting from the operating characteristics of the business model, this paper designs a BOO business model suitable for clean energy power generation and heating projects and a method for economic benefit analysis of clean energy power generation and heating projects from a value perspective under this business model.

\section{Business model design}

\subsection{PPP business model}

The PPP model means that in the field of public services, 
the government adopts a competitive method to select social capital with investment, operation and management capabilities[8-10]. The two parties conclude a contract in accordance with the principle of equal negotiation, and the social capital provides public services, and the government pays the social capital based on the results of public service performance evaluation. A more typical way is that the government and the private sector form a special purpose agency (SPV), introduce social capital, emphasize joint design and development and bear risks, and cooperate in project development and operation throughout the process. The operation mode of PPP includes BOT, BOO, PFI, BTO, ROT, etc.

The traditional mode of clean energy power generation and heating requires the power grid company to invest a lot of money, time and manpower in the preliminary planning, electric heating equipment selection and installation, household wiring renovation, grid upgrades, etc., and annual operation and maintenance costs will be increased in the later period. The most important thing is that the current subsidy policy for clean energy power generation and heating has a gradual withdrawal trend. Under the traditional mode, grid companies have undertaken a lot of economic pressure, which also reduces the enthusiasm and efficiency of power grid companies to carry out clean energy power generation and heating projects to a certain extent.

Since the service life of electric heating equipment is generally about 10 to 15 years, and the project investment is relatively large, the payback period is long, and the equipment property rights may not be transferred, so this paper selects the BOO operation mode as Operation mode of clean energy power generation and heating under PPP mode.

\subsection{Application of BOO mode in clean energy power generation and heating projects}

The clean energy power generation and heating project can be divided into two parts: equipment investment and power grid construction. For the power grid part, the power grid company assumes the role of the investor and undertakes the upgrading and transformation of the transmission and distribution grid. The transformation part of electric heating equipment undertakes equipment transformation investment and construction work through the establishment of a clean heating BOO project cooperation company. The specific investment carrier organization form is shown in Figure 1.

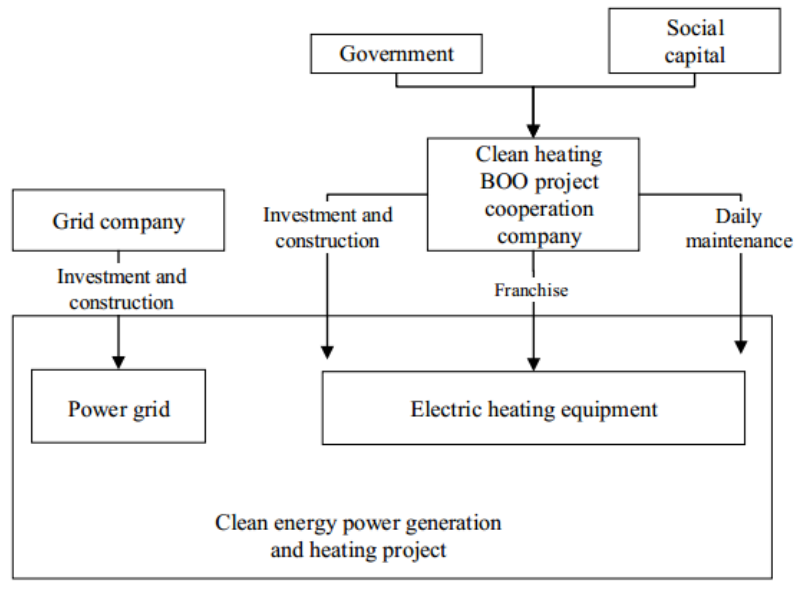

Fig. 1. Investment vehicle organization form

Among them, government departments invest in funds in the form of subsidies for electric heating equipment, which mainly plays a supervisory function. Social capital invests a lot of funds, accounting for most of the shares of the clean heating BOO project cooperation company, and mainly plays the role of decision-making and operating company. Figure 2 shows the operating mode of cooperative companies in the clean heating BOO project.

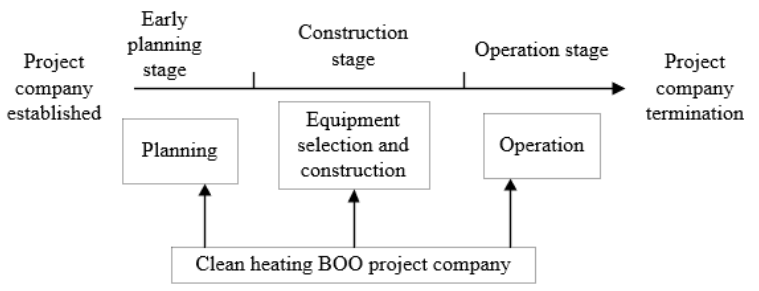

Fig. 2. Clean heating BOO project cooperation company operating model

The existence stage of the cooperative company of the clean heating BOO project includes: the pre-planning stage, the construction stage and the operation stage.

\section{Economic benefit analysis}

\subsection{Operational economic analysis method of cooperative company of clean heating BOO project}

This article chooses to evaluate the economic benefits from a value perspective. The specific method is to identify the pros and cons of the project by comparing the net present value, net annual value and net final value of different power construction project plans. In engineering practice, only the net present value method is generally used for comparison. Net Present Value (NPV) refers to the algebraic sum of the present value of each year's net cash flow calculated at the industry benchmark discount rate or other set discount rate during the project calculation period. Considering the time value of funds, the net present value of a project is equal to the total present value of future returns minus the total investment. If the net present value is greater than zero, it means that 
the investment project is feasible. If the net present value is less than zero, it means that the project cannot bring sufficient cash returns and the investment project is not feasible. The calculation formula is:

$$
N P V(t)=\sum_{t=0}^{n}(C I-C O)_{t}(1+t)^{-t}
$$

Where: $C I$ is cash inflow; $C O$ is cash outflow; $t$ is the number of calculation period; $i$ is the discount rate.

\subsection{Cash flow analysis of cooperative company of clean heating BOO project}

Clean heating BOO project company cash flow consists of two parts: cash inflow and cash outflow. The amount of cash outflow is mainly determined by the cost of electric heating equipment renovation and electricity purchase cost, and the amount of cash inflow is mainly determined by government subsidies and the income of electric heating.

For the cash outflow part, the cost of electric heating equipment transformation is invested in the construction phase, and the calculation formula is:

$$
C_{f i}=F \cdot C_{i}
$$

Where: $F$ refers to heating area, the unit is $m^{2}, C_{i}$ is the investment per unit area, the unit is yuan.

The main input in the operation phase is the electricity purchase cost. Suppose that after the clean energy power generation and heating project is carried out in a certain area, the number of users in the area is $W$ (the number of households), the average annual electricity consumption per household is $Q(\mathrm{kWh})$, and the power grid companies purchase electricity prices is $P_{0}$ (yuan) a8nd the power purchase cost is $D C$ (yuan), the formula for the annual power purchase cost of the grid company is expressed as follows:

$$
D C_{t}=W \cdot Q \cdot P_{0} \quad(t=1,2 \ldots, n)
$$

At the same time, in the operation stage, for the clean heating BOO project company, its main income comes from the user's heating fee $C_{h}$ in the heating season, that is, the corresponding expenses that users need to pay during the heating season. The settlement method depends on the heating method. The heating cost calculation method for users of decentralized heating is as follows:

$$
C_{h}=\sum_{i} p_{u i} \times P_{u i}
$$

Where: $i$ represents the peak, valley, and flat periods of electricity consumption; $p_{u i}$ is the corresponding electricity price for each period, and $P_{u i}$ is the electricity output of the electric heating equipment corresponding to each period.

\section{Case analysis}

\subsection{Project overview}

Take a clean energy power generation and heating project in a certain area of Xinjiang as an example. The project is planned to be implemented in two phases. The first phase of the project mainly transforms rural residents in the three prefectures who have better power grid conditions, higher coal prices, and economical implementation of clean energy power generation and heating, which involved about 932,000 households. The total investment is about 13.73 billion yuan, of which about 3.52 billion yuan (about 2.96 billion yuan for electric heating equipment investment and about 560 million yuan for household wiring renovation) undertaken by the cooperative company for the clean heating BOO project, accounting for the total investment estimate of $25.6 \%$.

In terms of government subsidies, the project can receive $65 \%$ of the central government's subsidies for the renovation of rural residential heating facilities (about 3.52 billion yuan). For the residents themselves, each resident considers the standards of 50 square meters of heating area and 4 kilowatts of heating facilities, and provides certain subsidies to families in need to ensure the most basic heating needs.

\subsection{Economic benefit analysis based on Net Present Value method}

This paper uses the NPV method to analyze the economic benefits of the operation of the clean heating BOO project cooperation company. In the calculations in this paper, the investment in the renovation of residential heating facilities at the initial stage of the project is considered to be invested in the $0^{\text {th }}$ year, and the government subsidies for the renovation of residential heating facilities are also considered to be subsidized in the $0^{\text {th }}$ year. The project started operating in the first year to generate revenue. The discount rate is calculated at $5 \%$ and the calculation period is 10 years. The cash flow of the clean heating BOO project cooperation company is shown in Table 1.

Table 1. Clean heating BOO project cooperation company cash flow statement

\begin{tabular}{cccccc}
\hline $\begin{array}{c}\text { Calculation } \\
\text { period }\end{array}$ & $\begin{array}{c}\text { Cash } \\
\text { inflow }\end{array}$ & $\begin{array}{c}\text { Cash } \\
\text { outflow }\end{array}$ & Net cash flow & $\begin{array}{c}\text { Cumulative net } \\
\text { cash flow }\end{array}$ & $\begin{array}{c}\text { Present value of } \\
\text { net cash flow (NPV) }\end{array}$ \\
\hline 0 & 22.88 & 35.2 & -12.32 & -12.32 & -12.32 \\
1 & 1.5844 & 0.178944 & 1.4055 & -10.9145 & 1.33857 \\
2 & 1.5844 & 0.178944 & 1.4055 & -9.5090 & 1.27483 \\
3 & 1.5844 & 0.178944 & 1.4055 & -8.1035 & 1.21412 \\
4 & 1.5844 & 0.178944 & 1.4055 & -6.6980 & 1.15631 \\
\hline
\end{tabular}




\begin{tabular}{rlllll}
\hline 5 & 1.5844 & 0.178944 & 1.4055 & -5.2925 & 1.10125 \\
6 & 1.5844 & 0.178944 & 1.4055 & -3.8870 & 1.04881 \\
7 & 1.5844 & 0.178944 & 1.4055 & -2.4815 & 0.99886 \\
8 & 1.5844 & 0.178944 & 1.4055 & -1.076 & 0.95130 \\
9 & 1.5844 & 0.178944 & 1.4055 & 0.3295 & 0.90600 \\
10 & 1.5844 & 0.178944 & 1.4055 & 1.735 & 0.86286 \\
\hline
\end{tabular}

It can be seen from Table 1 that for the clean heating BOO project cooperation company, the net present value of the clean energy power generation heating project during the operation stage of the clean energy heating project has a net present value greater than zero, indicating that the investment project is feasible and social capital can obtain a certain amount of income through the project. At the same time, it saves the power grid company the operating cost of transforming residential heating facilities, and enables the power grid company to obtain resource benefits such as time and manpower invested in planning. For residents, according to statistics, before the implementation of the clean energy power generation heating project, under the scenario of all residents using coal for heating, the average coal consumption per household in winter is about 3 tons, and the average heating cost per household is 3000 3300 yuan. After the implementation of the power generation heating project, the average household heating cost is about 1,700 yuan (heating area is about 50 square meters), which is much lower than the cost of coal-fired heating.

\section{Conclusion}

This paper adopts the BOO business model in clean energy power generation and heating projects, introduces social capital, and analyzes in combination with specific calculation examples. The results show that for social capital, the model is investable. For the power grid company, the power grid company can save a lot of resources and improve efficiency at the same time.

All in all, the BOO mode can save a lot of time, manpower, and investment for clean energy power generation and heating projects, reduce the pressure on the operation and maintenance of power grid companies, make up for the lack of equipment transformation technology and avoid many other difficult problems. Moreover, professional social forces with sufficient funds, advanced technology, and standardized management to maintain professional electric heating equipment have also promoted the growth of contracting enterprises. The introduction of the BOO model into clean energy power generation and heating projects has created a win-win situation for the environment, enterprises and society, which also provides new ideas for the consumption of new energy.

\section{References}

1. Y. Han, T. T. Zhang, J. Fang, Transp. R. 6, 2029(2020).

2. Y. X. Zhou, R. Gao, P. X. Tian, Urban Stud. 23, 2325(2016).

3. G. Luo, $\mathrm{N} \mathrm{Hu}$, Environ. Mon. Forew. 10, 1013+21(2018).

4. J. J. Liu, Y. J. Gu, S. B. Jiang, Electr. P. Technol. Econom. 18, 34-37(2006).

5. X. X. Chen, N. B. Liu, Pearl River Mod. Construct. 12, 27-29(2007).

6. Y Liu, Electr. P. Technol. Econom. 17, 46-49(2005).

7. H. F. Yang, Electr. P. Technol. Econom. 10, 4851(1998).

8. X. L. Ma, L Xu, Y. B. Gao, Mod. Hosp. 16, 720722(2016).

9. L. B. Li, Y. B. Gao. Mod. Hosp.. 16, 1793-1794, 1797(2016).

10. H. Y. Ding, Intel. City. 3, 32-34(2017). 